\title{
SPADIES*: Una estrategia de seguimiento a la deserción en la FUCS.
}

\author{
Sandra Cely**
}

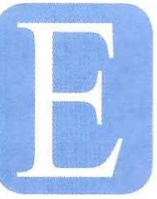

1 fenómeno de la deserción constituye quizás uno de los factores más críticos de las instituciones de educación superior que afecta los objetivos de cobertura y se ha convertido en un asunto de vital importancia para todo el sector, ya que tiene un alto impacto económico y social. Un ejemplo de ello es que para el año 2004 la deserción en el país se estimó en un 49\% y como causas de abandono más comunes se establecieron las limitaciones económicas, bajo rendimiento académico, desorientación vocacional y dificultades de adaptación a la vida universitaria.

La vicerrectoría de planeación y proyectos especiales preocupada por esta problemática en la FUCS, generó desde hace dos años un comité antideserción en el cual participan los secretarios académicos de las diferentes facultades, bienestar universitario, las oficinas de calidad, de orientación universitaria y planeación, cuyo propósito es hacer seguimiento a la deserción y generar estrategias de retención para los estudiantes de la universidad.

En busca de las estrategias de apoyo, la vicerectoría junto con bienestar universitario implementan el SPADIES, sistema antideserción para instituciones de educación superior, el cual hace parte de un conjunto de proyectos del Ministerio de Educación Nacional. Lo desarrolló para el MEN, mediante una consultoría otorgada por concurso público de meritos, el CEDE (centro de estudios sobre desarrollo económico) de la Universidad de los ANDES y con la interventoría del Centro de Investigaciones Económicas de la Universidad de Antioquia.

\footnotetext{
Sistema para la deserción en las instituciones de educación superior.

** Directora de Bienestar Universitario, Fundación Universitaria de Ciencias de la Salud, Bogotá D.C. Colombia.
}

El sistema es dinámico y funciona mediante la migración de datos de estudiantes matriculados, primíparos y graduados que han hecho parte de la FUCS desde 1999. Su análisis se hace por cohortes, basándose en el enfoque de historia de vida y se centra en el análisis de una secuencia de eventos. Implica el seguimiento a la hoja de vida de cada uno de los estudiantes a lo largo de su permanencia en la IES.

Este software tiene como característica que la información recopilada allí se cruza con tablas de información del ICFES e ICETEX, lo cual permite tener una información detallada por estudiante y su vulnerabilidad frente al problema de abandono estudiantil, ayudando a determinar causas de deserción, efectividad de las estrategias y en qué momento de la carrera estas generan un mejor impacto.

Otras tablas de información que son ingresadas al software como retiros forzosos, apoyos académicos y financieros, son entre otras, las variables que permitirán identificar problemáticas especificas de la FUCS. Esta herramienta fue entregada oficialmente a la Fundación en agosto de 2007 por la Universidad de los Andes y el MEN, junto con un informe de acompañamiento sobre deserción y teniendo como base la información suministrada hasta ese momento en el SPADIES.

Desde entonces bienestar universitario trabaja en la recopilación, actualización y migración de datos, con el fin de contar con información real y así lograr generar un programa antideserción, basado en el análisis que desde allí se establezca, teniendo en cuenta que es imprescindible contar con toda la información para el estudio y así lograr la detección oportuna de los grupos de riesgo, realizar seguimiento y brindar el apoyo necesario. 